\title{
Door System Lab. Terpadu UNIPMA Berbasis Intelligent Automatic Sebagai Penunjang New Normal
}

\author{
Ina Sunaryantiningsih*¹, Irna Tri Yuniahastuti ${ }^{2}$, Habi Angga Tristian ${ }^{3}$ \\ ${ }^{1,2,3}$ Universitas PGRI Madiun, Indonesia, Fakultas Teknik, Prodi Teknik Elektro \\ e-mail: *11inas@unipma.ac.id, ${ }^{2}$ irnatri@unipma.ac.id, ${ }^{3}$ anggahabi11@gmail.com
}

\begin{abstract}
Abstrak
Kebiasaan baru di era pandemi membuat kita harus hati-hati untuk menyentuh semua benda, tidak terkecuali adanya pembatasan access pada lab terpadpun juga diterapkan. Untuk mempermudah pengidentifikasian dosen, mahasiswa dan karyawan yang akan berkegiatan dilab terpadu maka dibuatlah door system dengan menggunakan QR Code sebagai switching pintu otomati. QR code sendiri berisi data pribadi yang diambil dan terhubung dengan SIM (Sistem Informasi Manajemen) UNIPMA. Setiap dosen, mahasiswa dan karyawan dapat mengaccess QR Code dari SIM masing-masing. QR Code bersifat unik sehingga setiap orang akan mendapatkan QR Code yang berbeda. Penggunaan QR Code sebagai switching Door system yang dipindai menggunakan wabcame dengan cover akrilik tembus cahaya dan dengan spesifikasi Door System yang dapat dioperasikan pada beban 100kg, panjang lintasan $180 \mathrm{~cm}$, dengan opening/closing speed door atau forward/backward pada motor rata rata 10/45 cm/s, dan dengan hold-open time 0,5-30s
\end{abstract}

Kata kunci-Akses terbatas, DC motor, Identifikasi otomatis, Kontrol, QR code

\begin{abstract}
New habits in the pandemic era make us have to be careful to touch all objects, not to mention that there are also restrictions on access to the laboratory. To make it easier to identify lecturers, students and employees who will be carrying out activities in an integrated laboratory, a door system was created using QR Code as an automatic door switching. The $Q R$ code itself contains personal data taken and connected to the UNIPMA SIM (Management Information System). Each lecturer, student and employee can access the QR Code from their respective SIM. QR Code is unique so that everyone will get a different $Q R$ Code. The use of $Q R$ Code as a switching Doorr system that is scanned using a wabcame with a translucent acrylic cover and with a Door System specification that can be operated at a load of 100kg, a track length of $180 \mathrm{~cm}$, with opening / closing speed door or forward / backward on an average 10/45 motor. $\mathrm{cm} / \mathrm{s}$, and with a hold-open time of 0.5-30s
\end{abstract}

Keywords-Automatic identification, Control, DC motor, Limited Access, QR code 


\section{PENDAHULUAN}

Dunia telah mengalami musibah yang membuat hati seluruh penduduknya bersedih. Covid-19 telah merenggut kebebasan kita dalam beraktivitas diluar rumah, protocol kesehatan telah di wajibkan dan kita sebagai warga yang patuh dengan aturan dan sekaligus paham dengan dampak covid-19 harus mematuhinya demi kebaikan bersama. Sehingga terciptanya kebiasaan baru yang harus dilakukan demi menjaga diri dan orang-orang disekitar kita. Teknologi dan perkembangannya dapat mempermudah kita melalui new normal. Lab terpadu unipma selama pandemi membatasi akses masuk para dosen dan karyawan, untuk para mahasiswa perkuliahan dilakukan secara daring. Yang menjadi masalah adalah ada beberapa mata kuliah praktik yang akan sulit jika tidak dilakukan di Laboratoriun. Karena pembatasan akses penggunaan lab. terpadu maka dibuatkan sistem cerdas untuk memudahkan dosen, mahasiswa dan karyawan tanpa harus meminta ijin pada security.

Universitas PGRI Madiun memiliki sistem manajemen yang telah terkomputerisasi yaitu Sistem Informasi Manajemen (SIM) dimana setiap komponen yang terdapat di UNIPMA terhubung dalam SIM UNIPMA. Untuk mahasiswa memiliki account di SIM Akademik (SIAKAD) dam Karyawan memiliki account di SIM Kepegawaian sedangkan dosen memiliki dualaccess.

Teknologi yang berkembang memudahkan kita dalam memanfaatkan hardware maupun software untuk kehidupan sehari-hari disini penulis menggunakan manfaat webcame. Webcame sendiri merupakan kamera digital yang memiliki kemampuan menangkap gambar yang bergerak.

Pada penulisan kali ini penulis akan memanfaatkan pengunaan wabcam sebagai alat untuk mengidentifikasi Quick Respone Code dengan metode image processing. Dimana QR Code sendiri menggunakan empat mode pengkodean yaitu numeric, alfanumerik, byte/biner, dan kanji yang diolah dan dijadikan sebagai kunci atau dijadikan access untuk membuka pintu lab terpadu.

Webcame yang digunkan untuk alat scan bQR Code mengolah image atau citra menjadi informasi yang tersimpan pada bitmap. Dimana setip bit membentuk dot atau titik informasi yang dikenal sbagai pixel.

Jadi setiap dosen mahasiswa dan karyawan akan mendapatkan QR code yang yang bisa di download pada SIM mereka untuk di capture denggan menggunakan wabcame kemudian akan disingkronkan dengan image yang telah tersimpan dalam database SIM, Sehingga access pintu bisa terbuka karena ada singkronisasi QR code.

\section{METODE PENELITIAN}

Metode penelitian perancangan sistem yang dipakai yaitu pengembangan sistem waterfall development Model. Dan untuk perancangan sistem sendiri terbagi menjadi 2 bagian yaitu prototype mekanik dan perancangan softwarenya dimana prinsip kerja dari 
alat yang digunakan yaitu menghubungkan dua sistem yaitu sistem penyimpanan identitas yang dapat diambil dari SIM UNIPMA dan menghubungkan penyimpanan data dengan sistem control yang menggunakan mikroprosesor dengan pembacaan $b Q R$ Code yang dibangun di dalam SIM sesuai dengan data pribadi Dosen, mahasiswa dan karyawan.

\subsection{Perancangan Prototype Hardware}

Untuk perancangan idealnya, prototype memiliki fungsi sebagai identifikasi kebutuhan perangkat lunak sehingga akan didesain sebuah alat untuk pengambilan image barcode yang telah di unduh pada SIM. Perancangan alat pada Door system yang akan digunkan terdiri dari motor DC penggerak pintu yang berbasis mikrocontroler dan wabcam sebagai proses pencitraan barcode dengan menggunakan wabcam Logitech c525 8mp dengan cover tembus cahaya dari bahan akrelik dengan jarak pencitraan barcode antar 5 sampai $15 \mathrm{~cm}$ dimaksudkan agar proses pencitraan lebih akurat.

Perancangan Rangkaian mekanik motor DC pengerak Door sistem terdiri dari: Rancangan Catu Daya rangkaian digunakan untuk merubah tegangan AC ke DC. Dan juga sebagai penstabil tegangan. Rangkian Mikrokontroler sebagai otak yang mengatur jalannya sistem secara menyeluruh digunakan ATMega 8535. Rangkaian Motor DC sebagai mesin penggerak pintu door sistem dengan pengaturan data menggunakan IC L293D.

\subsection{Perancangan Software}

Proses perancangan software memiliki tiga tahapan yang berbeda yaitu tahapan image dimana tahapan ini memproses image dari barcode yang di download dari SIM dosen, mahasiswa dan karyawan yang didalamnya terdapat informasi identitas diri, proses penentuan Range total pixel hitam dan proses pengidentifikasian QR Code dan singkronisasi antar software dan mekanik door system agar terbuka secara otomatis ketika data sudah tervalidasi. 


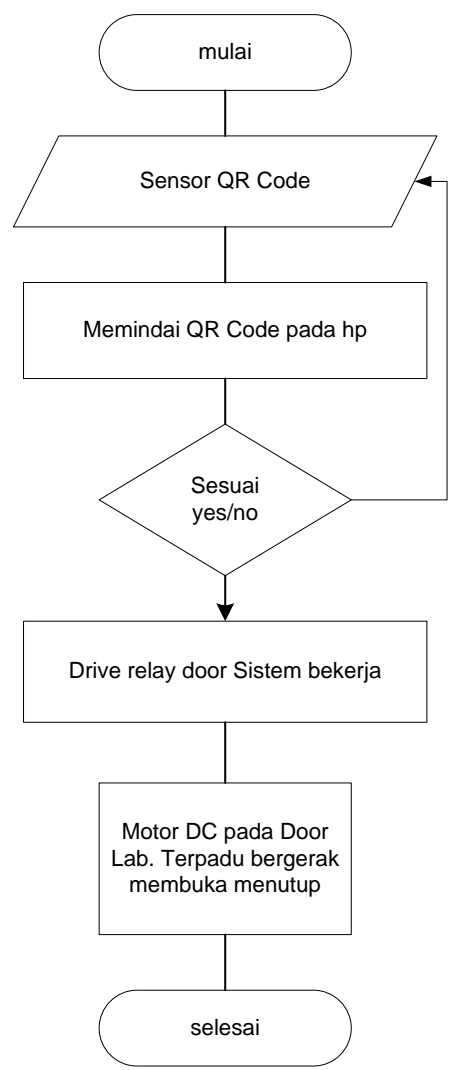

Gambar 1 Flowchart Proses Door Sistem Bekerja

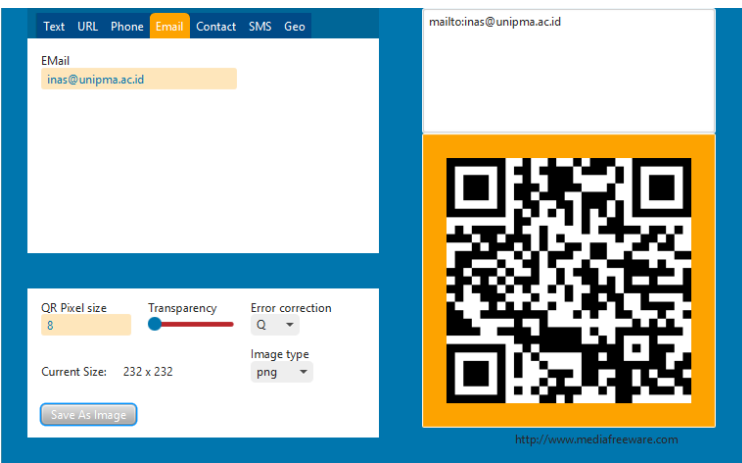

Gambar 2 QR Code Generator

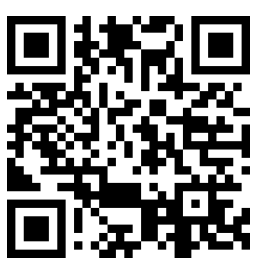

Gambar.3

QR Code untuk Inas@unipma.ac.id

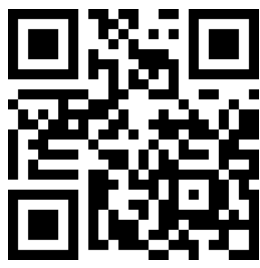

Gambar.4

QR Code untuk no.hp.082141642447 


\section{HASIL DAN PEMBAHASAN}

Door sistem sebagai penggerak pintu otomatis terdiri dari webcam pemindai QR code sebagai pengamanan dan switching, sensor ini akan menyimpan database semua dosen, mahasiswa dan karyawan yang diambil dari data base SIM UNIPMA.yang langsung terhubung dengan Drive relay yang digunakan untuk forward and backward dari motor DC. Ada dua pengujian yaitu pengujian terhadap identifikasi QR Code yang yang dilakukan dengan 3 posisi dengan pencahayaan yang sama, tegak lurus, kondisi miring dan kondisi dimana pencahayaan dirubah dengan posisi tegak pada webcame.

Yang kedua pengujian pada sistem pengerak otomatis motor DC pada Pintu yang telah di atur oleh mikroprosesor pada drive relay Door system. Pengujian posisi dan pencahayaan yang telah dilkukan mendapatkan hasil sebagai berikut:

Tabel 1 Tabel Pengujian Posisi dan Pencahayaan

\begin{tabular}{|c|c|c|c|c|}
\hline Identitas Pegawai & QR Code & Posisi & Pencahayaan & Detection Rate \\
\hline \multirow{4}{*}{ inas@unipma.ac.id } & \multirow{4}{*}{ 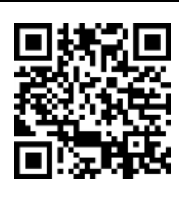 } & \multirow{2}{*}{ Tegak lurus } & Terang & $90 \%$ \\
\hline & & & Redup & $90 \%$ \\
\hline & & \multirow{2}{*}{ Miring } & Terang & $80 \%$ \\
\hline & & & Redup & $80 \%$ \\
\hline \multirow{4}{*}{ irnatri@unipma.ac.id } & \multirow{4}{*}{ 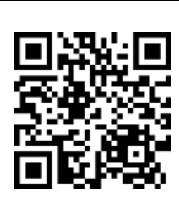 } & \multirow{2}{*}{ Tegak lurus } & Terang & $90 \%$ \\
\hline & & & Redup & $90 \%$ \\
\hline & & \multirow{2}{*}{ Miring } & Terang & $80 \%$ \\
\hline & & & Redup & $80 \%$ \\
\hline \multirow{4}{*}{ bayuf@unipma.ac.id } & \multirow{4}{*}{ 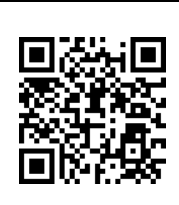 } & \multirow{3}{*}{ Tegak lurus } & Terang & $90 \%$ \\
\hline & & & Redup & $90 \%$ \\
\hline & & & Terang & $80 \%$ \\
\hline & & Miring & Redup & $80 \%$ \\
\hline
\end{tabular}

Tabel 2 Data Forward Motor DC

\begin{tabular}{ccccc}
\hline Massa $(\mathrm{Kg})$ & Voltage & Current (Amp) & rpm & Time (s) \\
\hline 20 & 60 & 2.5 & 2400 & 10 \\
60 & 180 & 3 & 2900 & 30 \\
100 & 230 & 3.5 & 3500 & 50 \\
\hline
\end{tabular}

Tabel 3 Data Backward Motor DC

\begin{tabular}{ccccc}
\hline Massa $(\mathrm{Kg})$ & Voltage & Current (Amp) & rpm & Time (s) \\
\hline 20 & 60 & 2.5 & 2400 & 10 \\
60 & 180 & 3 & 2900 & 30 \\
100 & 230 & 3.5 & 3500 & 50 \\
\hline
\end{tabular}


Tabel 4 Technical Data Door System Parameter Beban Maksimal

\begin{tabular}{cll}
\hline \multicolumn{3}{l}{ Technical Data Beban Maksimal } \\
\hline 1 & Height & $100-150$ \\
2 & Depth & 180 \\
3 & Massa & 100 \\
4 & Opening speed & $10-50 \mathrm{~cm} / \mathrm{s}$ \\
5 & Closing speed & $10 / 40 \mathrm{~cm} / \mathrm{s}$ \\
6 & Hold-open time & $0,5-30 \mathrm{~s}$ \\
7 & Voltege & $230 \mathrm{v}$ \\
8 & frequency & $50 / 60 \mathrm{~Hz}$ \\
9 & Power & $250 \mathrm{w}$ \\
\hline
\end{tabular}

\section{KESIMPULAN}

Untuk menunjang era New Normal dan memudahkan pembatasan dan pengidentifikasian pengunjung lab terpadu UNIPMA maka dari serangkaian pembuatan dan pengujian Door system pintu laboratorium terpadu UNIPMA dengan webcam sebagai pemindai QR code yang berfungsi sebagai switch motor DC dari door system telah dilakukan.

1. Untuk posisi QR Code yang di intentifikasi webcame dalam pengujian cahaya tidak menjadi pengaruh besar pada sistem ini, hal ini dipengruhi jenis webcame yang dipilih adalah webcame yang memiliki autofocus.

2. Pada kondisi optimal dari forward dan backward untuk penggunaan door system dapat mengerakkan dengan berat sampai dengan $100 \mathrm{~kg}$ dengan daya yang dibutuhkan 180 watt dengan tegangan 230 volt dengan waktu yang digunakan perdetik dapat membuka antara 10 sampai $50 \mathrm{~cm}$.

\section{DAFTAR PUSTAKA}

[1] Acmad, B. dan K Firdausy, “Teknik pengolahan citra digital menggunakan Delphi”. Ardhi Publising. Yogyakarta 2005

[2] A.S Rosa, "Landasan teori Thinning," Bandung, 2008

[3] D. Bambang and M. Awaludin, "Penajaman dan segmentasi citra pada pengolahan citra digital". Bandung. 2010

[4] Mujiman, "Pintu otomatis berpengunci waktu berbasis mikrokontroler AT89C51," Jurnal Teknologi, vol.1, No.1, 2008

[5] Zuhal, "Dasar teknik tenaga listrik dan elektronika daya," Gramedia, Jakarta 1988 